\title{
Experience of Implementing Moisture Sorption Control in Historical Archives
}

\author{
P. Zítek, T. Vyhlídal, J. Chyský
}

This paper deals with a novel approach to inhibiting the harmful impact of moisture sorption in old art works and historical exhibits preserved in remote historic buildings that are in use as depositories or exhibition rooms for cultural heritage collections. It is a sequel to the previous work presented in [2], where the principle of moisture sorption stabilization was explained. Sorption isotherm investigations and EMC control implementation in historical buildings not provided with heating are the main concern in this paper. The proposed microclimate adjustment consists in leaving the interior temperature to run almost its spontaneous yearly cycle, while the air humidity is maintained in a specific relationship to the current interior temperature. The interior air humidity is modestly adjusted to protect historical exhibits and art works from harmful variations in the content of absorbed moisture, which would otherwise arise owing to the interior temperature drifts. Since direct measurements of moisture content are not feasible, the air humidity is controlled via a model-based principle. Two long-term implementations of the proposed microclimate control have already proved that it can permanently maintain a constant moisture content in the preserved exhibits.

Keywords: Equilibrium moisture sorption, preventive conservation, sorption isotherm, humidity control.

\section{Introduction}

All over Europe, the oportunities for preserving most of the cultural heritage are intimately connected with the use of historical buildings - castles, mansions, palaces, monasteries etc. - to deposit historic and artistic collections, and with opening these buildings to public access. The microclimate regulations for this class of preservation are still a subject of controversial discussions [8]. As regards the Czech Republic, the interiors of more than 250 castles and mansions serve as exhibition rooms for authentic historic and/or artistic collections, as archives, historical libraries, etc. In approximately one third of these buildings valuable collections of paintings and sculptures are presented, although neither heating nor air-handling devices are in operation in most of these interiors. Hence there is almost no way to achieve a stable and non-aggressive internal environment. Reusing historic sites to keep historic and artistic collections is common in many countries, and owing to this an invaluable part of Europe's cultural heritage is exposed to the more or less damaging impact of an unsuitable microclimate in historical buildings, particularly to the impact of air humidity, [1], [2]. Internal air humidity is the most significant harmful exposure for exhibits made of porous organic materials, such as wood, paper, canvas, etc. More specifically, variations in air humidity and temperature during the annual cycle cause variations in moisture content in these mostly organic materials and cause dimensional changes which may lead to dangerous stresses and deformations, and may even openup cracks [7]. In earlier research, the authors developed a microclimate control system aimed at keeping the moisture content in the protected exhibits constant. The idea of moisture content stabilization is based on the sorption isotherm model of a selected material for which a constant moisture content is achieved by adequate humidity adjustment to compensate for the temperature changes given by their natural annual cycle.

This paper reports on the implementation and successful trial operation of a MOL-26 dehumidifying device, controlled according to the equal-sorption principle in the interior of the Historica Collection in the State Archives in
Třeboň Castle, Czech Republic, where microclimate control has been tested over a period of more then twenty two months. The paper explains the equal-sorption approach to environment adjustment including the specific issue of the different sorption characteristics of various materials. The design of the dehumidification device control unit is based applying the Henderson model and implementing a microprocessor. The implementation in an archive is described, and the resulting environment parameters are reported and discussed.

\section{Equilibrium moisture content model}

For each of the considered materials the equilibrium moisture content (EMC) $u$ determines a specific level appropriate to the relative humidity $\varphi$ and temperature $T$ of the ambient air. The EMC value increases with growing $\varphi$ and decreases with growing $T$ and, in general, it is much more sensitive to changes in air humidity than to variations in temperature. Various models, e.g. these by Day and Nelson [3], Simpson [4], Henderson [5], are used to describe the relationship between EMC as $u$, and the pair of air temperature $T$ and relative air humidity $\varphi, u=\Psi(\varphi, T)$. Unfortunately these investigations have dealt with the higher temperature ranges of EMC relevant to industrial purposes, far from the temperatures typical for preventive conservation. The relationship $\Psi($.$) is usually displayed in the coordinates \varphi$ and $u$, as so-called sorption isotherms, with temperature considered as a parameter. The logarithmic Henderson model was chosen as the most suitable available model, namely its three-parameter version [5]

$$
u=\left[\frac{-\ln (1-\varphi)}{A(T+B)}\right]^{C},
$$

where $\varphi \in\langle 0,1\rangle$ is the relative air humidity expressed as a dimensionless ratio, $T$ is air temperature in ${ }^{\circ} \mathrm{C}$ and $u$ is EMC, expressed as the ratio of moisture mass content to the mass of anhydrous material. The parameters of the model are specific for each material, the additive temperature constant $B$ is in ${ }^{\circ} \mathrm{C}, C$ is a positive dimensionless exponent less than one and 
the sensitivity coefficient $A$ is in ${ }^{\circ} \mathrm{C}^{-1}$. The model is clearly not suitable for air humidity approaching the state of saturation, i.e. for $\varphi \rightarrow 1$, since then the logarithm is not defined. However, any state that is approaching saturation brings about condensation, and thus such a state is quite inadmissible for the interiors that we are considering here.

A common feature of most EMC models and measurements available from the references is that they have a higher temperature range than is needed for our work. The temperature range of the microclimate adjustment will be approximately from $5{ }^{\circ} \mathrm{C}$ to $25^{\circ} \mathrm{C}$, but the EMC characteristics are seldom available for these temperatures. We therefore decided to perform our own EMC measurements to find the truest possible parameters of the Henderson model (1) for the purposes of microclimate control in historical interiors.

\section{Investigations of moisture sorption in wood and paper samples}

In order to assess the parameters of the Henderson model, in cooperation with the Department of Carbohydrate Chemistry and Technology, Institute of Chemical Technology in Prague, we performed several long-term experiments to assess the sorption isotherms for the following samples of materials, namely a pine wood sample new (PWn), an oak

wood sample-new (OWn), pine wood samples-around hundred years old (slightly rotten PWo1, well-preserved PWo2), a paper sheet sample taken from a book fifty years old (PSo). The average size of the wood samples were $8 \times 8 \times 40 \mathrm{~mm}$. The samples of paper consisted of a bunch of 40 paper sheets $50 \times 50 \mathrm{~mm}$ in size. For more than three weeks these samples were examined in different combinations of temperature and relative humidity, maintained by temperature control and humidity adjustment by adding specific saturated salt solutions of hygroscopic agents in four dessicators, [6], see Table 1.

The conditions inside the dessicators were monitored by Testo 175-H1 dataloggers. The experiment, which consisted in periodic weighing of the wood samples, lasted 22 days after which the saturated weights of the samples were determined. Then the samples were dried up and the dried residua were weighed again to determine the equilibrium moisture content

Table 1: Conditions inside the dessicators

\begin{tabular}{c|c|c|c} 
Dessicator & Saturated salt solution & $\mathrm{RH}[\%]$ & $T\left[{ }^{\circ} \mathrm{C}\right]$ \\
\hline 1 & $\mathrm{NaCl}$ & 77 & 6.0 \\
2 & $\mathrm{NaCl}$ & 77 & 22.3 \\
3 & $\mathrm{Mg}\left(\mathrm{NO}_{3}\right)_{2}$ & 63 & 7.0 \\
4 & $\mathrm{Mg}\left(\mathrm{NO}_{3}\right)_{2}$ & 56 & 22.3
\end{tabular}

Table 2: Equilibrium moisture content estimates of samples stored in dessicators, and parameters of the Henderson model for each set of samples

\begin{tabular}{l|c|c|c|c|c|r|r}
\multirow{2}{*}{} & \multicolumn{4}{|c|}{ Equilibrium moisture content $[\mathrm{g} / \mathrm{g}]$} & \multicolumn{3}{c}{ Henderson model param. } \\
\cline { 2 - 8 } & $77 \%, 6{ }^{\circ} \mathrm{C}$ & $77 \%, 22.3{ }^{\circ} \mathrm{C}$ & $63 \%, 7{ }^{\circ} \mathrm{C}$ & $56 \%, 22.3{ }^{\circ} \mathrm{C}$ & $A\left[{ }^{\circ} \mathrm{C}^{-1}\right]$ & $B\left[{ }^{\circ} \mathrm{C}\right]$ & $C$ \\
\hline PWn & 0.150 & 0.136 & 0.115 & 0.092 & 0.247 & 95.83 & 0.668 \\
\hline OWn & 0.138 & 0.120 & 0.102 & 0.084 & 0.361 & 80.02 & 0.653 \\
PWo1 & 0.166 & 0.146 & 0.130 & 0.103 & 0.425 & 62.81 & 0.601 \\
PWo2 & 0.154 & 0.137 & 0.121 & 0.096 & 0.431 & 68.88 & 0.605 \\
\hline
\end{tabular}

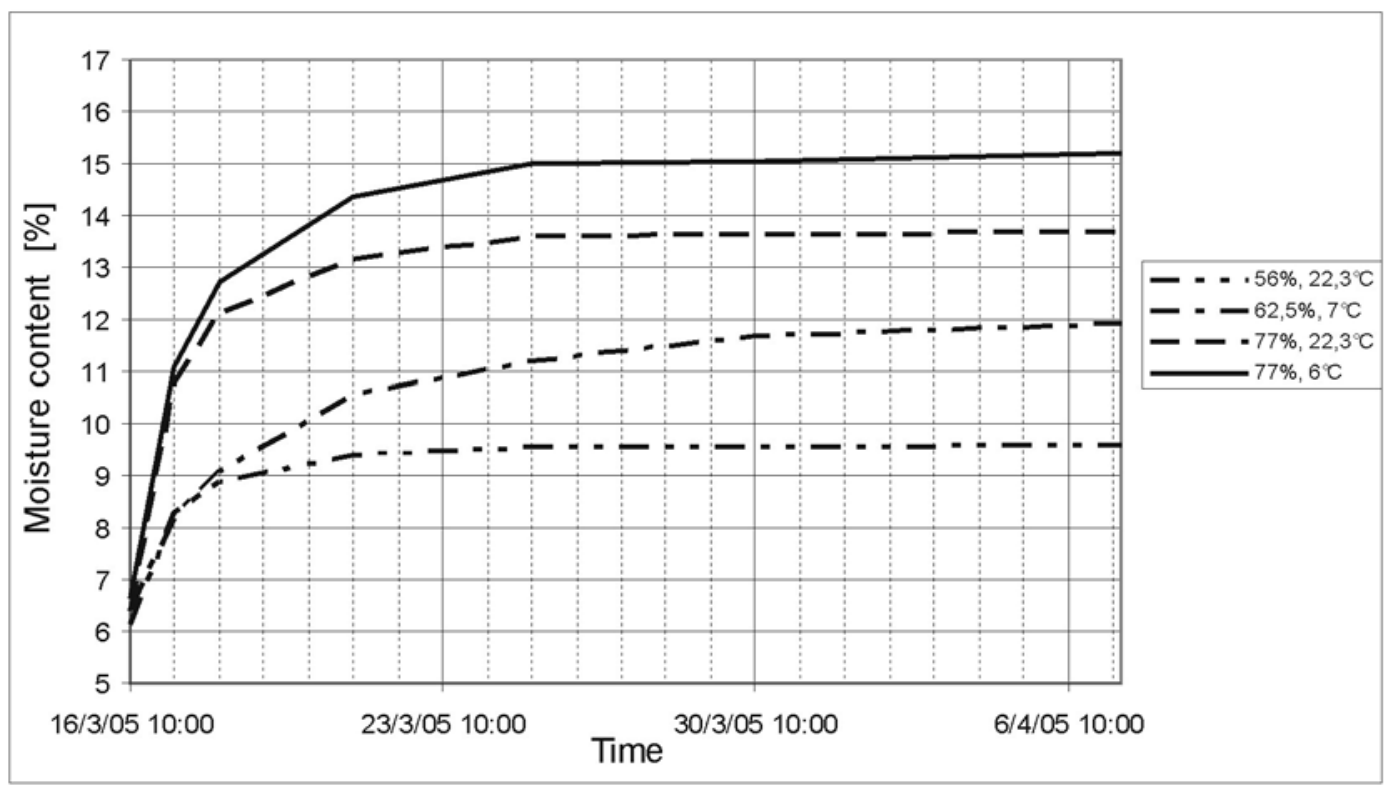

Fig. 1: The moisture content in the samples PWo2 during the experiment 
(EMC), see Table 2. This table also shows the parameters of the Henderson model resulting from the measurements.

As an example of the sorption dynamics, the time evolution of the moisture content in the PWo2, samples is shown in Fig. 1. In fact, the results shown in the figure are step responses. The step changes in the conditions are caused by taking the samples from an environment with average temperature $T=22{ }^{\circ} \mathrm{C}$ and relative humidity $R H=40 \%$ (usual interior conditions) and placing them in dessicators with the microclimate characterized by the values shown in Table 1 . As can be seen from the responses, the sorption dynamics are relatively slow even though the samples only weight three grams. It can be concluded from the responses that the EMC fluctuations caused by the natural changes in temperature and relative humidity during a daily cycle are quite negligible. However, the longer term fluctuations in the environment caused by alternations of sunny and rainy periods, especially in the spring and autumn seasons, can cause considerable fluctuations in moisture content, particularly in artifacts with thin layers on the surface. Fig. 2 shows the sorption isotherms computed according to the Henderson model with the parameters obtained for the PWo2 samples. The experimental results show significant differences in the temperature sensitivity of EMC in the lower temperature range. The experiments also show that not only the material of the sample, but also its age, plays a considerable role in the sorption behavior.

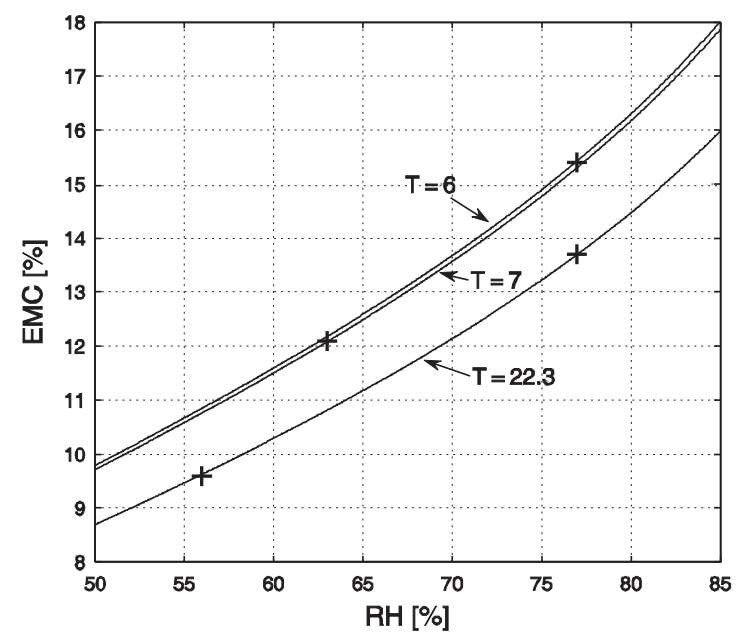

Fig. 2: Experimental fitting of the sorption isotherms by the Henderson model for wood samples PWo2 (pine, old), + - EMC measurement according to Table 2

\section{Maintaining constant EMC by air humidity adjustment}

Model (1) was designed to assess the moisture content in particular materials. However, it also contains an intuitive suggestion for forming microclimate conditions that will keep this moisture content constant. It is apparent from (1) that for a temperature change from $T_{1}$ to $T_{2}$ such a specific humidity change from the initial $\varphi_{1}$ to a new $\varphi_{2}$ can keep the EMC value constant i.e. $u_{1}=u_{2}$. Since the change in moisture content is the crucial harmful impact originating from the air humidity, this is the main factor in preventive conservation. Using (1), the requirement $u_{1}=u_{2}$ leads to the following relationship dependent only on parameter $B$ (while $A, C$ cancel each other out)

$$
\frac{\ln \left(1-\varphi_{1}\right)}{\left(T_{1}+B\right)}=\frac{\ln \left(1-\varphi_{2}\right)}{\left(T_{2}+B\right)}
$$

Our idea for preventing variations in moisture sorption consists in the following. The control stabilizing the moisture content in the preserved exhibits is conceived as a reference tracking humidity control, where the modestly variable reference humidity value $\varphi_{\mathrm{D}}$ the desired air humidity is assessed from the temperature and humidity measurements by means of relationship (2), i.e.

$$
\varphi_{\mathrm{D}}=1-\exp \left[\ln \left(1-\varphi_{0}\right) \frac{T+B}{T_{0}+B}\right],
$$

where $T_{0}, \varphi_{0}$ is a selected reference air state satisfying the preventive conservation claims and $T$ is the actual (measured) interior temperature. This desired $\varphi_{\mathrm{D}}$ is applied as the reference setting for a humidity control adjusting the actual (measured) interior humidity $\varphi$ towards $\varphi_{\mathrm{D}}$ by means of an air handling device.

Strictly speaking, as mentioned above, this control protect only a single material - corresponding to parameter $B$ considered in (3) - from variations in the moisture content. However although various materials differ from each other in their sorption characteristics, it can be seen from (2) that the differences in parameter $B$ values influence the required humidity readjustment only weakly. Take, for instance, two materials $M$ and $N$, having sorption parameters $B_{M}$ and $B_{N}$ respectively, and assume an air state change from the initial air state $T_{0}, \varphi_{0}$ to a different temperature $T$ and try to assess the new desired humidity values as $\varphi_{M}$ and $\varphi_{N}$ for materials $M$ and $N$ respectively. Using equality (2), the following equations are obtained for the two materials

$\frac{\left(T+B_{M}\right)}{\left(T_{0}+B_{M}\right)}=\frac{\ln \left(1-\varphi_{M}\right)}{\ln \left(1-\varphi_{0}\right)}, \quad \frac{\left(T+B_{N}\right)}{\left(T_{0}+B_{N}\right)}=\frac{\ln \left(1-\varphi_{N}\right)}{\ln \left(1-\varphi_{0}\right)}$.

The additive temperature constant $B$ takes on relatively high values, say from 60 to $200{ }^{\circ} \mathrm{C}$, for various materials of the considered protected exhibits while, however, the temperature range assumed in this study is only from about 5 to $25^{\circ} \mathrm{C}$. Apparently, the higher $B$ is the less sensitive the material is to changes in moisture sorption. It is easy to prove that the temperature ratios in (4) are close to one, even if there are substantial differences in $B$. Consequently the humidity logarithm ratios are also close to one and therefore the required humidity readjustments $\varphi_{M}-\varphi_{0}$ and $\varphi_{N}-\varphi_{0}$ have rather low values and cannot differ from each other substantially. For example, the required humidity readjustment for the pine wood assessed above differs only by about one per cent from the values appropriate for other sorts of wood, e.g. oak, beech etc. A similar conclusion can be arrived at for other moisture sensitive materials, e.g. various sorts of paper, canvas, parchment etc. With regard to the attainable accuracy level of the humidity measurements, these mutual differences are negligible and the readjustment of air humidity resulting from (2) can be considered as satisfactory not only for wood in general but also for miscellaneous exhibits of paper, canvas, parchment, etc. The only exception to this rule is a painting or an artefact on an interior wall. In this case the humidity readjustments needed to prevent the surface moisture content from varying are substantially higher than for the other cases 
mentioned. Hence, as a general rule, variations in EMC are inhibited by humidity readjustments which are only weakly dependent on differences in the sorption properties of various materials.

The humidity adjustments resulting from relations (2) or (3) may seem very modest. However these values cannot be viewed separately since they are to be compared with the spontaneous changes on relative humidity brought about by temperature variations. Using the derivative of the Magnus formula [7] for the humidity mixing ratio $\mu$, in $\mathrm{g} / \mathrm{kg}$

$$
\mu=3.795 \varphi \exp \left(\frac{a T}{b+T} \ln 10\right)
$$

with the parameters $a=7.5$ and $b=237.3^{\circ} \mathrm{C}$, the condition of keeping $\mu$ constant results in the following approximate relationship for a change from air state $T_{0}, \varphi_{0}$ to another air state $T, \varphi$

$$
\varphi-\varphi_{0} \cong-\frac{a b \ln 10}{\left(b+T_{0}\right)^{2}} \varphi_{0}\left(T-T_{0}\right) .
$$

For example, if $\varphi_{0}=0.5$ and $T_{0}=20{ }^{\circ} \mathrm{C}$ a temperature decrease, e.g. to $T=15{ }^{\circ} \mathrm{C}$ in a well insulated room brings about an increase of relative humidity by more than fifteen per cent. By contrast, the derivatives of the Henderson model (1)

$$
\begin{aligned}
& \frac{\partial u}{\partial T}=\left[\frac{-\ln (1-\varphi)}{A(B+T)}\right]^{C} \frac{(-C)}{(B+T)}<0, \\
& \frac{\partial u}{\partial \varphi}=\frac{C}{[A(B+T)] C} \frac{[-\ln (1-\varphi)]^{C-1}}{(1-\varphi)}>0
\end{aligned}
$$

prove that a humidity adjustment according to (2) providing no change in EMC requires a decrease of $\varphi$, in this case by about 1.5 to $2.0 \%$. Hence, instead of the natural relationship, where the relative humidity in a well insulated room increases when the temperature decreases, an inverse proportion between these two variables is to be artificially provided by equal-sorption control. Humidity readjustment (2) thus brings about a more substantial intervention into the air state than at first appears. The desired relationship between $T$ and $\varphi$ to be artificially provided by the control results from the requirement $\mathrm{d} u=0$. The following relationship is obtained from the derivatives $(7)$

$$
\begin{aligned}
& \Delta \varphi=-\frac{\partial u / \partial T}{\partial u / \partial \varphi} \Delta T=K_{C}(T, \varphi) \Delta T \\
& K_{C}(T, \varphi)=\frac{\ln (1-\varphi) \mid(1-\varphi)}{B+T}>0,
\end{aligned}
$$

where the gain parameter $K_{C}(T, \varphi)$ is a function of both temperature and air humidity. It should be noted that only $B$ from the three Henderson model parameters influences this gain parameter. Due to the opposite trends of $(1-\varphi)$ and $|\ln (1-\varphi)|$, and also due to the relatively high value of $B$, $B \geq 60{ }^{\circ} \mathrm{C}$, the variability of $K_{C}(T, \varphi)$ with humidity and temperature is fairly weak. In fact, owing to the limited accuracy of $T$ and $\varphi$ measurements, the relationship (8) can be treated as linear.

\section{Performance estimation of the air handling device}

In order to perform the above-discussed humidity adjustments, an air handling device was applied in a historic interior. The required performance of this device results from the volume and humidity parameters of the protected room. To achieve the desired relative humidity $\varphi_{\mathrm{D}}$ in the room it is necessary to exhaust, or sometimes to add, an amount of water per hour $q_{M}$. Therefore $\varphi_{\mathrm{D}}$ is to be expressed as the desired humidity mixing ratios $\mu_{\mathrm{D}}$ and $\mu_{\mathrm{E}}$ appropriate to the indoor and outdoor air states, using the Magnus formula (5). Considering $\mu_{\mathrm{W}}$ as the humidity mixing ratio on the internal surface of the walls, the total transferred moisture amount $q_{M}$ is given as

$$
q_{M}=Q_{\mathrm{L}}\left[\mu_{\mathrm{E}}-\mu_{\mathrm{D}}\right]+D_{\mathrm{W}}\left[\mu_{\mathrm{W}}-\mu_{\mathrm{D}}\right],
$$

where $Q_{\mathrm{L}}$ is the in-leakage of the outdoor air and $D_{\mathrm{W}}$ is the effective diffusion coefficient between the entire wall surface and the internal air. If $q_{M}>0, q_{M}$ is the performance of the dehumidifier, on the contrary $q_{M}<0$ means the humidifying water input requirement. The values of absolute humidity are computed from the measured temperature and the relative humidity values by means of the Magnus formula (5). The in-leakage flow of the outdoor air is usually estimated to be approximately 25 to $40 \%$ of the room volume per hour [8]. The moisture diffusion from the walls is highly variable. Our measurement shows that the moisture diffusion from rather wet walls may be as significant a water source as window leakage for the interior. The performance of the dehumidifying device has to be designed to manage even the highest demands of moisture transport throughout the annual cycle of the weather in the site. However, there is only exceptionally a need for humidification in remote historic buildings, and its provision can be often omitted to reduce costs.

\section{Implementation in the Třebon archives}

The first implementation of the proposed microclimate adjustment in the Chapel of the Holy Cross at Karlštejn Castle proved its ability to provide permanently favourable conditions for keeping the absorbed moisture constant in most of the exhibits deposited in the medieval interior [1], in spite of extreme demands due to large numbers of visitors.

Another implementation of the proposed humidity adjustment operates in the Historica Collection in the State Archives in Třeboň Castle, Czech Republic, using the MOL-26 dehumidifying device, produced by PZP Komplet, Dobruška, Czech Republic. This apparatus is controlled according to the equal sorption principle (3), see Fig. 3. Before the dehumidifying device was installed in the collection room in 2005, its environment had been long-term monitored. The annual cycle measurements performed in the interior, shown in Fig. 4, show that the temperature does not fall below zero even in the coldest winter periods. Secondly, a comparison of the measured relative humidity with its desired value computed from the Henderson model to maintain constant EMC (10\% for wood, parameters for PWol in Table 2) shows that only dehumidifying is needed. Thus, the dehumidifying device is able to provide a favourable microclimate in this interior throughout the whole year. 


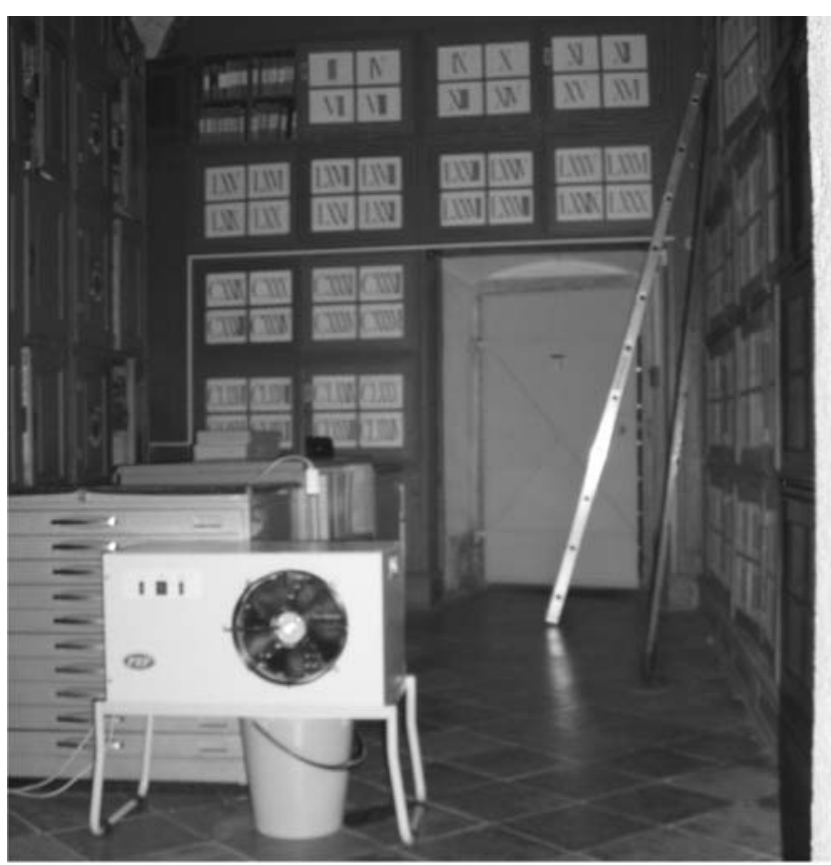

Fig. 3: Interior of Historica collection in Třeboň archives with dehumidifying device MOL-26

A special control unit was developed to control the MOL-26 dehumidifying device. The main parts of the control unit are the Atmel AT89C2051 eight-bit microcontroller and the SHT11 temperature-humidity sensor (produced by SENSIRION AG, with a capacitive polymer moisture-sensing element for relative humidity (0 to $100 \% \mathrm{RH}$ ) and a bandgap temperature sensor $\left(-40^{\circ} \mathrm{C}\right.$ to $\left.120^{\circ} \mathrm{C}\right)$. The two parts are connected by a two-wire SENSIRION serial bus. The microcontroller processes the data measured by the tempera- ture/humidity sensor. A data table for predefined types of objects is stored in the memory of the control unit. From this the program assigns the desired relative humidity value $\varphi$ to each measured temperature sample $T$ according to (3). Consequently, the desired $\varphi_{\mathrm{D}}$ is compared with the measured $\varphi$, and on the basis of this comparison, the program algorithm decides whether the dehumidifier is to be switched on or off. Thus the control unit accomplishes a relay based control, where the reference value of desired relative humidity $\varphi_{\mathrm{D}}$ is assigned by (3) on the basis of measured temperature $T$. The algorithm operates with the hysteresis $0.5 \% \mathrm{RH}$ and the time delay of 5 min limit the switching frequency, in accordance with the operating conditions for the MOL-26 dehumidifier. The control unit is powered by an external AC adapter $230 \mathrm{~V}$ AC/9 V DC, $100 \mathrm{~mA}$.

Two examples of records of the controlled environment in the archives are shown in Fig. 5 and 6 . As can be seen, for both paper and wood materials EMC is almost constant, which is in agreement with the primary aim of the control. Comparing the EMC characteristics in Fig. 5 and 6 with those in the uncontrolled environment shown in Fig. 4 in the same time period, we can clearly see the improvement brought about by implementing the control method described in this paper.

\section{Conclusions}

The proposed principle of the equal-sorption humidity control principle involves adjusting the relative indoor air humidity to a level continuously adapted to the indoor air temperature according to condition (3), where the desired humidity is determined by temperature measurements. As the air handling processes are much faster than the dynamics of the EMC changes, correcting the humidity can easily forestall changes in moisture sorption, and in this way the control is

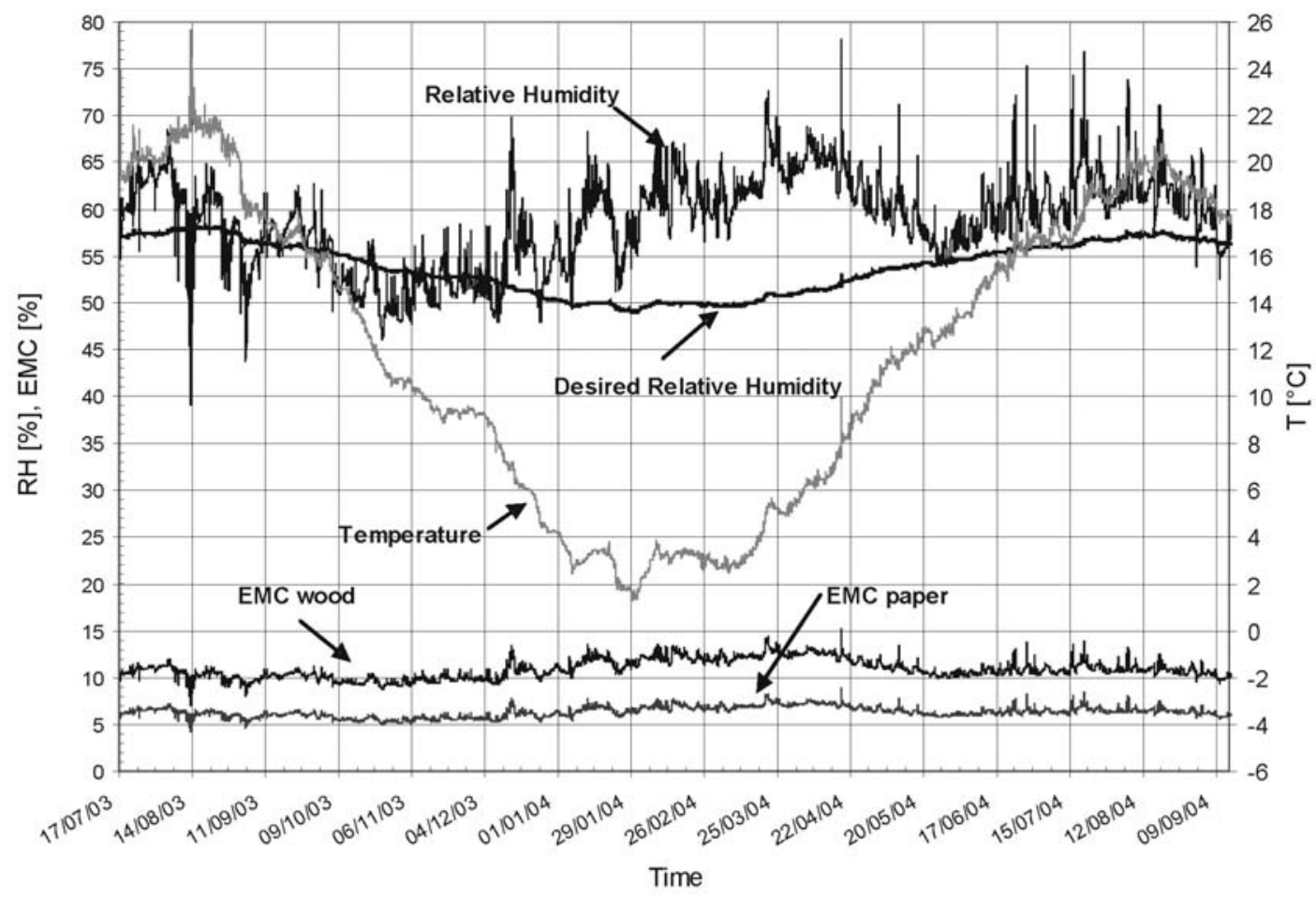

Fig. 4: Records of the uncontrolled environment in Historica Collection of Třeboň Archives and the proposed relative humidity adjustment for desired EMC $u_{\mathrm{D}}=10 \%$ 


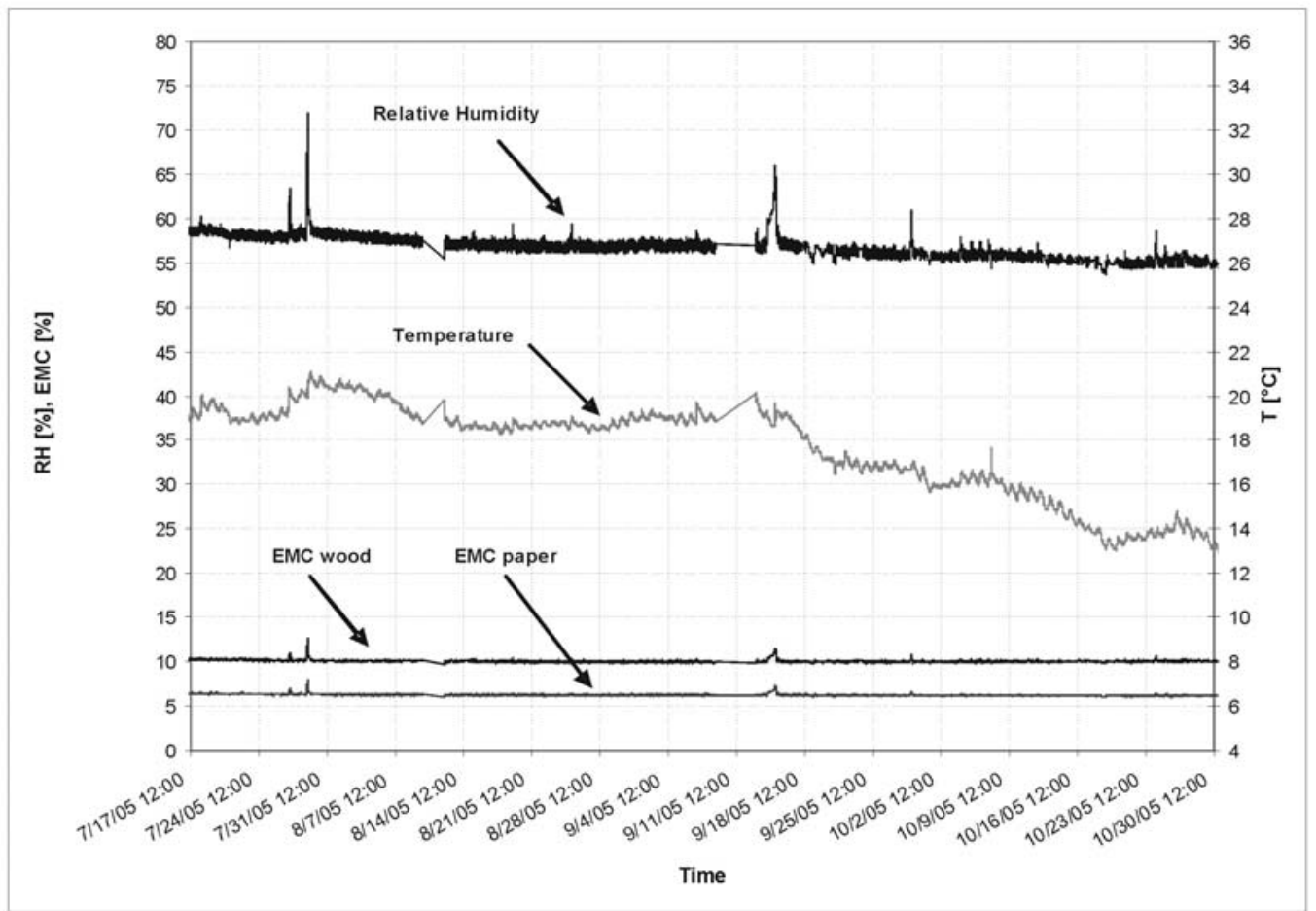

Fig. 5: Records of the controlled environment in Historica Collection of Třeboň Archives - time period from 17. 7. 2005 to 30. 10. 2005

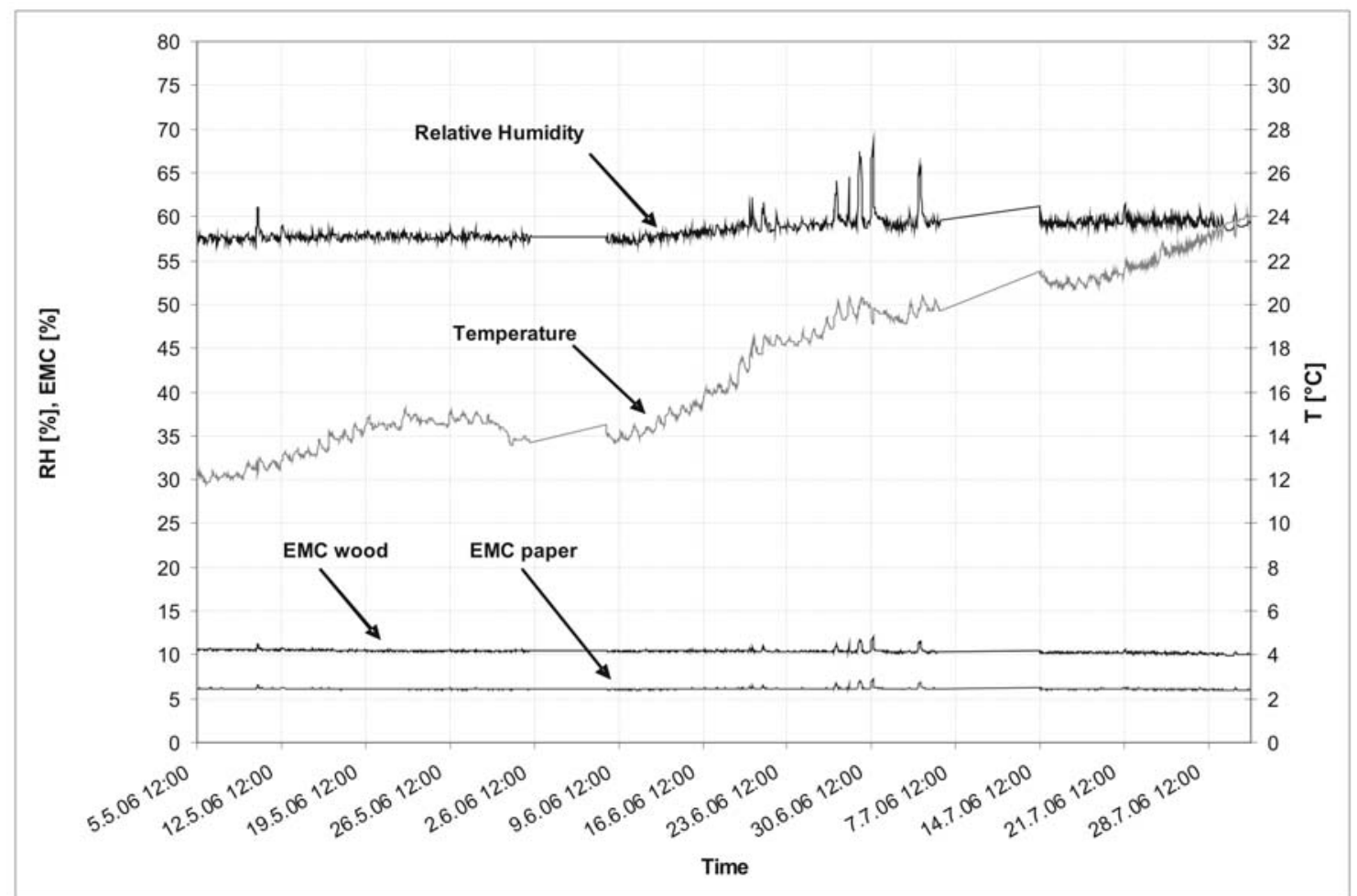

Fig. 6: Records of the controlled environment in Historica Collection of Třeboň Archives - time period from 5. 5. 2006 to 1. 8. 2006

endowed with a predictive character. Although the moisture content is viewed as the controlled variable, no acceptable method for measuring real-time EMC is available. The presented model-based control scheme presented here is therefore to be applied. The dehumidifying devices are designed as local apparatuses, preferably portable. If they are portable the staff can put them in the most suitable place in the interior. In addition, Low-power dehumidifiers can be produced for a reasonable price. The air handling device is controlled to operate interruptedly, producing low-amplitude oscillations of humidity around the desired $\varphi_{\mathrm{D}}$. For implementation purposes, the authors' own measurements of sorption isotherms were of primary importance, since relevant data for typical preventive conservation materials were available. The crucial point for the proposed microclimate adjustment was the finding that, despite differences in sorption characteris- 
tics for various organic materials such as wood, paper, canvas, parchment, etc., the desired humidity corrections can be considered as universal for all of them. The main contribution of the paper consists in the implementation results since the proposed control has shown long-term effectiveness in maintaining the interior air in a state that stabilizes the absorbed moisture in moisture-sensitive materials.

\section{Acknowledgment}

The research presented here has been supported by the Ministry of Education of the Czech Republic under Project No. 1M0567.

\section{References}

[1] Zítek, P., Němeček, M., Vyhlídal, T., Kopecká. I.: Moisture Sorption Stabilization as a Preventive Conservation Technique. $6^{\text {th }}$ European Commmission Conference on Sustaining Europe's Cultural Heritage, London 2004.

[2] Zítek, P., Vyhlídal, T.: Model-Based Control of Moisture Sorption in a Historical Interior. Acta Polytechnica, Vol. 45 (2005), No. 4, Prague: CTU Publ. House.

[3] Avramidis, S.: Evaluation of "Three-Variable" Models for the Prediction of Equilibrium Moisture Content in Wood, Wood Science and Technology, Springer-Verlag 1989.

[4] Simpson, T. W.: Predicting Equilibrium Moisture Content of Wood by Mathematical Models. Wood and Fiber, 1973, Vol. 5, p. 41-49.

[5] Henderson, S. M.: A Basic Concept of Equilibrium Moisture, Agr. Eng. Vol. 33, 1952, p. 29-33.

[6] Greenspan, L.: Humidity Fixed Points of Binary Saturated Aqueous Solutions. Journal of Research of the $\mathrm{Na}$ - tional Bureau of Standards, Physics and Chemistry. Vol. 81 (1977), No. 1, p. 89-96

[7] Camuffo, D.: Microclimate for Cultural Heritage. Amsterdam, London: Elsevier Science Ltd., 1998.

[8] Kotterer, M.: Research Report of the Project EU 1383 PREVENT, Museum Ostdeutsche Galerie Regensburg, 2002.

Prof. Ing. Pavel Zítek, DrSc.

phone: +420224352564

e-mail: Pavel.Zitek@fs.cvut.cz

Centre for Applied Cybernetics

Department of Instrumentation and Control Engineering

Doc. Ing. Tomáš Vyhlídal, Ph.D.

phone: +420224352877

e-mail: Tomas.Vyhlidal@fs.cvut.cz

Centre for Applied Cybernetics

Jan Chyský

phone: +420224352469

e-mail: Jan.Chysky@fs.cvut.cz

Department of Instrumentation and Control Engineering

CTU in Prague

Faculty of Mechanical Engineering

Technická 4

16607 Praha 6, Czech Republic 